\title{
JULIO GONZÁLEZ Y HANS HARTUNG, VÍNCULOS DE ABSTRACCIÓN*
}

\author{
CARMen Fernández APARICIO ${ }^{1}$ \\ Museo Nacional Centro de Arte Reina Sofía
}

\begin{abstract}
Este artículo estudia la relación artística entre el escultor Julio González y el pintor Hans Hartung entre 1937 y los primeros cuarenta, dentro de un panorama dominado por un creciente interés por la abstracción. Se revisa las obras de ambos artistas, su recepción crítica y las exposiciones en las que participaron en relación con una abstracción de síntesis expresiva previa al Informalismo.
\end{abstract}

Palabras clave: Julio González; Hans Hartung; Abstracción en Francia años treinta; Escultura moderna en hierro.

\section{JULIO GONZÁLEZ AND HANS HARTUNG, JOINED IN ABSTRACTION}

This article explores the artistic relationship between the sculptor Julio González and the painter Hans Hartung from 1937 to the early 1940s in Paris, within an artistic panorama dominated by a growing interest in abstraction. Reviewed are the connections between their respective works, their critical reception and the exhibitions in which both participated, in relation to a synthetic expressive Abstraction previous to Abstract Expressionism.

Key words: Julio González; Hans Hartung; Abstract art in France in the 1930s; Modern Sculpture in Iron.

Cómo citar este artículo / Citation: Fernández Aparicio, Carmen (2018): "Julio González y Hans Hartung, vínculos de abstracción”. En: Archivo Español de Arte, vol 91, núm. 363, Madrid, pp. 301-316. https://doi.org/10.3989/ aearte.2018.19.

Los artistas que a mediados de los años treinta tuvieron la agudeza de interesarse por la escultura de Julio González, convirtiéndose en sus particulares discípulos, terminaron cumpliendo con un destacado papel en la definición del arte de los cincuenta en París y en Norteamérica. El ejemplo más conocido fue el de David Smith, el escultor que representó la nueva escultura en los Estados Unidos, que publicó en 1956 un texto esencial para la recepción crítica de González en base a la innovación del uso de la soldadura y a la definición de una nueva sintaxis escultórica, titulado: "González, primer maestro del soplete"2. El otro ejemplo de afinidad electiva, sobre el que se centra este escrito, fue el que se refiere al pintor Hans Hartung ${ }^{3}$, quien además de llevar a cabo una práctica en paralelo a la del escultor en el período inmediato al inicio de la Guerra Mundial, desempeñó el papel de pionero de la abs-

\footnotetext{
$1 *$ Este trabajo se debe al apoyo de la Fondation Hartung-Bermang de Antibes que dirige actualmente Thomas Schlesser. Agradezco la colaboración de Bernard Derderian y Jean-Luc Uro.

carmen.fernandez@museoreinasofia.es / ORCID iD: http://orcid.org/0000-0001-9211-8548.

2 Para la redacción de su artículo Smith (Smith, 1956: 34-37, 64-65. y McCoy, 1973: 99-104) contó con los testimonios de dos personas cercanas a Hartung como Roberta González y Henri Goetz.

3 Se trata en: Stoulling, 1991; Merkert, 1992: 49-57; Abadie, 1992; Koidl, 2005: 295-301 y Claustres, 2006: 54-73.
} 
tracción durante la postguerra en Francia tras una profunda colaboración con el escultor catalán. Su ejemplo constata la influencia que el lenguaje escultórico de Julio González tuvo en la generación artística de los cincuenta y en el caso del artista alemán con especial relevancia para su pintura.

David Smith aún no se había decidido por la escultura cuando tuvo la intuición de acercarse a la obra González, por influencia de artistas norteamericanos que habían vivido en París como el también crítico y coleccionista John Graham y el miembro de Cercle et Carré y de Abstraction-Création, Jean Xceron ${ }^{4}$. El uso de una técnica industrial como la soldadura autógena y un concepto plástico original surgido de los hallazgos espaciales del cubismo analítico atrajeron a Smith que a partir de su ejemplo defendió, desde 1940, una abstracción basada en la articulación del espacio y en un nuevo lenguaje de "escultura sin bloque", según expresión de González, con la que su escultura buscó tener las mismas posibilidades expresivas que la pintura, además de reflejar una idea heroica e independiente de la labor del $\operatorname{artista}^{5}$. La textura irregular de la soldadura oxiacetilénica y el método de ensamblaje de piezas metálicas de diversa naturaleza, introducidos por González, también sirvieron para que buena parte de la escultura europea de los cincuenta buscara la expresividad vital a través de la forma abierta, y como señaló William Tucker, que esto ocurriera tanto si se trataba de obra figurativa o abstracta, construida o modelada ${ }^{6}$.

Si Smith fracasó en su intento de conocer personalmente a Julio González en 19357, Hartung consiguió incluso trabajar en el taller del artista que valoraba como uno de los mayores escultores de su generación ${ }^{8}$. González y Hartung coincidieron como expositores en la muestra Origines et développement de l'art international contemporain. De Cézanne à l'art nonfiguratif, inaugurada en julio de 1937 en el Jeu de Paume. La exposición presentaba por vez primera en un museo oficial francés una revisión de la vanguardia internacional hasta la abstracción, en el mismo período en el que la Exposition International des Arts et techniques dans la vie moderne, reflejaba el auge del totalitarismo político, donde Julio González mostró su particular concepto de realismo social con la escultura en hierro, la Montserrat (Stedelijk Museum de Amsterdam), en el jardín del Pabellón de España en el que se exponía el mural Guernica.

Al Jeu de Paume González acudió con la gran escultura Femme au miroir, ca. 1936-37 (Instituto Valenciano de Arte Moderno) la obra más ambiciosa de su nuevo lenguaje escultórico, mientras que el joven Hartung conseguía un destacado éxito al participar, dos años después de instalarse en París, con una gran pintura del año anterior, T.1936-14 (Musée National Centre Georges Pompidou) que asumía la libertad de trazo y la fuerza de Kandinsky. Hans Hartung describió el encuentro del pintor de 32 años se acercó al artista español de más de 60:

"Dans cette exposition figuraient des sculptures de Julio González, un artiste dont j'avais déjà remarqué avec beaucoup d'intérêt quelques sculptures à la galerie Pierre Loeb ${ }^{9}$. Je le rencontrai le jour du vernissage de l'exposition internationale; tout de suite nous avons eu une forte sympathie l'un pour l'autre. J'admirai son œuvre et González s'intéressa à ma peinture"10.

\footnotetext{
${ }^{4}$ Sobre esta relación artística: Fernández, 2008 y Fernández, 2011.

5 McCoy, 1973: 38[“On Abstract Art 1940”, pp. 37-40] y 119 [“The Artist and Nature. 1955”, pp. 116-118].

6 Tucker, 1974:83. Podríamos mencionar a escultores como Reg Butler, Lynn Chadwick o Anthony Caro, este último especialmente influido por Smith, además de los informalistas españoles, o figurativos como Marino Marini.

7 En compañía de John Graham y de su primera esposa Dorothy Dehner, Smith intentó visitara González en estudio en París, pero no pudieron localizar al escultor que se encontraba en Arcueil (Brenson, 2011: 75).

8 Hartung, 1976: 125.

9 Hartung conocía su obra al menos desde mayo de 1937; ese día asistió a la inauguración de su exposición en la Galerie Pierre, del 12 al 26 de mayo de 1937, y lo anotó en su agenda (Documento: Peint-RV/ A/ agenda 1937, Archivo Fondation Hartung Bergman (AFHB).

10 Hartung, 1976: 117.
} 
Seguidamente se produjo una convivencia artística en el taller del escultor en Arcueil, que tras el matrimonio de Hartung con la pintora Roberta González en 1939 ${ }^{11}$, se convirtió en un lazo familiar en el que se vivió la frustración al fin de la Guerra Civil española y la amargura de la separación de la familia en los últimos meses de vida del escultor, fallecido en Arcueil en marzo de 1942, cuando, en una Francia ocupada, el matrimonio Hartung-González se refugió en Lot ${ }^{12}$. En este período el pintor convivió con la obra de profundo contenido humano de González, cuando reflejaba su máxima angustia y madurez plástica. El admirable catálogo de sus esculturas y la gran producción de dibujos de esos años, inspiraron un diálogo artístico que se basaba en la condición de maestro de González y en su ascendiente en la vanguardia. Hartung asumió de forma sutil y profunda su peso en el desarrollo de su obra de los cincuenta, cuando la abstracción ya fue hegemónica en Francia y él uno de sus verdaderos pioneros. Y al evocar esos años en su Autobiografía, expuso también una idea absoluta de abstracción que le afianzaba en la generación informalista y que González no pudo asumir:

"Il [González] —escribe — me reprochait - d'inventer des formes qui n'existaient pas dans la nature, que Dieu n'avait pas créées. [...] J'essayais de lui démontrer que dans ses œuvres aussi, il y avait des formes qui étaient loin d'être une reproduction de la nature. Qu'il en usait même très librement. Eh bien, il me prouvait le contraire. Il me montrait comment, à partir de dessins figuratifs, lentement, il en arrivait à la forme 'abstraite' de ses sculptures". [...] "J'avais beau lui certifier que je ne voulais aucunement faire concurrente à Dieu, il n'en démordait pas: 'Tu n'as pas le droit " $"$.

\section{Julio González y la abstracción de síntesis}

Desde el inicio de la década de 1930 la discusión sobre el arte abstracto en París se centraba en sus posibilidades para la expresión de las emociones y en las inciertas expectativas de su evolución ${ }^{14}$, en paralelo al discurrir de grupos que seguían la línea geométrica derivada del cubismo como Cercle et Carré, fundado por Michel Seuphor y Joaquín Torres García en 1930, el efímero y rival Art Concret de Teo Van Doesburg y Abstraction-Création, nacido en $1931^{15}$. Entonces París también acogía a los pioneros de las dos corrientes de la abstracción: Piet Mondrian, que vivió en la ciudad de 1919 a 1938, y Wasily Kandinsky, que desde 1934 pasó sus últimos 11 años de vida en la ciudad; y a otros artistas más jóvenes como Joan Miró y Jean Arp que exploraban el automatismo surrealista introduciendo en sus obras signos de la naturaleza y elementos fortuitos. En 1936, las obras de estos dos artistas, que ya habían logrado un temprano apoyo crítico de la revista Cahiers $d^{\prime} A r t^{16}$, eran vistas como abstracciones derivadas de las for-

${ }^{11}$ La boda con la única hija de Julio González se celebró en Arcueil el 22 de julio de 1939, dos años después de la separación del pintor y la pintora Anna-Eva Bergman. El matrimonio finalizó en 1952, cuando Hartung se reencontró con su primera esposa, aunque el divorcio fue efectivo en 1956.

12 Hartung que fue voluntario de la Légion étrangère, escribe: “... Dès mon arrivée à Lasbouygues où, après tout, la famille González ne s'était réfugiée qu'à cause de moi, j'avais ressenti un pénible désarroi”. Hartung, 1976: 145.

13 Hartung, 1976: 125.

14 La revista Cahiers d'Art publicó en 1931 una encuesta, en la que participaron Mondrian o Kandinsky, Léger o Arp, sobre los desafíos, posibilidades y evolución del arte abstracto.

15 En 1932 se publicó el primer número de Abstraction-créatión, art non figuratif, con Arp, Gleizes, Hélion, Kupka, Tuntundjan, Valmier y Vantongerloo en el comité director. En 1934 la asociación contó con las bajas de Arp, TaeuberArp, Hélion, Delaunay, Pevner y Gabo.

16 En 1931 Christian Zervos (Zervos, 1931: 399-401) incluyó a estos dos artistas el grupo al que saludaba como nueva generación que se enfrentaba al objeto para constituir su propia poética. Georges Hugnet (Hugnet, 1931: 335337), considera a Miró un artista inclasificable y en 1934 Will Grohmann (Grohmann, 1934: 11-58 y 38 ) define su obra por los fragmentos de realidad y las formas libres. En la misma revista, Arp era visto en 1934 como un artista ligado a 
mas naturales ${ }^{17}$ y el propio Kandinsky los diferenciaba del surrealismo por la cualidad específicamente pictórica de sus obras ${ }^{18}$.

Cuando en otoño de 1935 Hans Hartung se instala en París, tras pasar tres años en Menorca, su pintura, que Sweeney definió por sus elocuentes ritmos lineales, se inspira en Kandinsky (fig. 1) y Miró (figs. 2 y 3) para buscar la expresión subjetiva lejos de la abstracción geométrica. En este período Julio González estaba inmerso en el trabajo personal de hacer escultura a base piezas de hierro y soldaduras, que desembocó en su conocida colaboración con Pablo Picasso para la realización de las construcciones metálicas del pintor entre 1928 y 1933. La novedad de la obra de González fue más allá de la innovación técnica; en estos años, creó una sintaxis nueva que apartándose de la cita textual del objeto encontrado, propia de la escultura en hierro de Picasso, lograba una obra estructurada en base a líneas de fuerza y signos fragmentarios de la naturaleza que se desvinculaba de las ideas de contorno y forma cerrada y se refería a la luz y al vacío como elementos positivos.

Las varillas y planos metálicos angulados de la escultura de González eran formalmente muy diferentes a las obras de Jean Arp o de Joan Miró, pero expresaban una misma resistencia a las estrictas ideas de abstracción o surrealismo, a la vez que mantenían contactos y confluencias entre ambas tendencias. La "casi abstracción" de Miró concordó con la original cita de la realidad de la escultura de Julio González, que, a pesar de la marcada independencia del artista, también compartió espacios de recepción crítica con Arp o Miró ${ }^{19}$. González expuso en algunas muestras de arte constructivo ${ }^{20}$, y aunque se puede decir que su escultura fue esencialmente una profundización en el espacio cubista, su plástica también guarda fuertes concomitancias con el surrealismo. Por ejemplo, sus figuras punzantes y distorsionadas se relacionan claramente con las turbadoras formas metamórficas con las que Picasso representaba la figura femenina en los años treinta ${ }^{21}$; sus esculturas lineales de los primeros años treinta sintonizan con las pinturas sobre papel Ingres que Joan Miró realiza en 1931, donde las líneas y los colores difuminados definen figuras ortogonales y planas, mientras que los sombríos lienzos de 1933-36 a base de formas distorsionadas y dramáticas de Miró, abordan un sentido similar al de las esculturas híbridas y enigmáticas que Julio González realizó en torno a los años de la guerra civil. Y en definitiva, la relación entre los signos abstractos con una fuerte sensación de realidad que el mismo escultor calificó por su aire extraño ${ }^{22}$, y la representación de la expresión subjetiva y la fuerza del signo vital de la pintura de Joan Miró, explicaría también la atracción que Hans Hartung sintió por la escultura del español.

En 1934 se celebró una importante exposición monográfica de Julio González en la galería de Cahiers d'Art, que sirvió para dar a conocer su obra entre críticos tan importantes como James Johnson Sweeney y Alfred J. Barr ${ }^{23}$, que vincularon su obra con la expresividad de Joan Miró y

la escritura automática e independiente del surrealismo pictórico y de la abstracción geométrica (Brzekowski, Jan, 1934:197-200).

17 Alfred Barr (Barr Jr., 1936: 12-13, 19) distingue entre Pure-abstractions, sin relación con la naturaleza y Nearabstractions, en la que se partía de la forma natural. Arp y Miró fueron asociados a la tendencia no geométrica que caracterizó con la forma de "la ameba", y que probablemente fue sugerida por la lectura de Jakovski.

18 El 15 de noviembre de 1936, escribe: “Les surréalistes n'ont pas assez de talents 'picturaux' pour paraître dangereux. C'est pour ça qu'ils attèlent à leur chariot des artistes qui n'ont que peu de choses à voir avec le surréalisme — par ex. Arp, Miró" (Boissel, 1998: 89).

19 William Jeffet (Jeffett, 1994. 126-135) explicó las conexiones formales de los tres.

20 González participó en 1933 en la muestra del Grupo Arte Constructivo, que Torres García organizó en Madrid y en el tercer número de la revista Abstraction-Création, de 1934, compuesto por Vantongerloo, se reprodujo la obra de González Petite tête au triangle, una obra que perteneció a Hartung; la presencia de González en la exposición "Thèse, anthitèse, syntèse" de 1935 de Lucerna, también le relaciona, inicialmente con Abstraction-Création.

${ }^{21}$ Sobre el surrealismo de Julio González escriben recientemente: Curtis, 2000: 72-85 y Parigodis, 2001-3: 54-64.

${ }^{22}$ Al referirse a la escultura de Picasso: "Des œuvres vraiment nouvelles qui ont souvent l'air bizarre", estaba hablando de su propia obra. González, Julio: Picasso et les cathédrales. Picasso sculpteur, ca. 1931-32. Archivo Instituto Valenciano de Arte Moderno (AIVAM), Fondo Julio González, n. ${ }^{\circ}$ 1816-1837. También en Tabard, 1999: 115-126.

${ }_{23}$ Carta de James Johnson Sweeney, 9 de noviembre de 1939, Archivo Instituto Valenciano de Arte Moderno (AIVAM), Fondo Julio González, n. ${ }^{\circ}$ 1863. Barr se lo recordó a Zervos en una carta de 4 octubre de 1955 (Derouet, 2006: 164). 


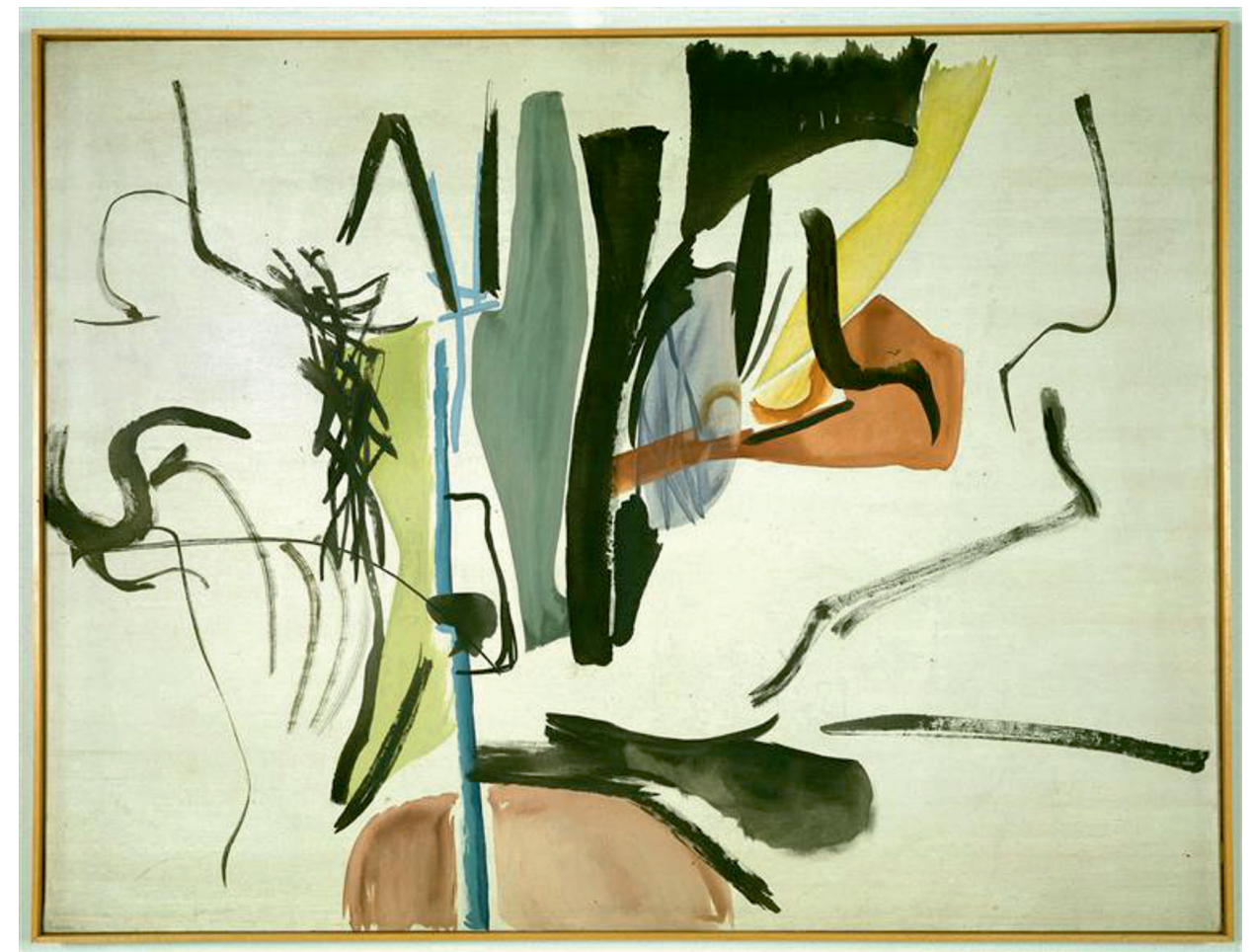

Fig. 1. Hans Hartung, T.1935-1, 1935. Oleo sobre lienzo, Musée National Georges Pompidou, París.

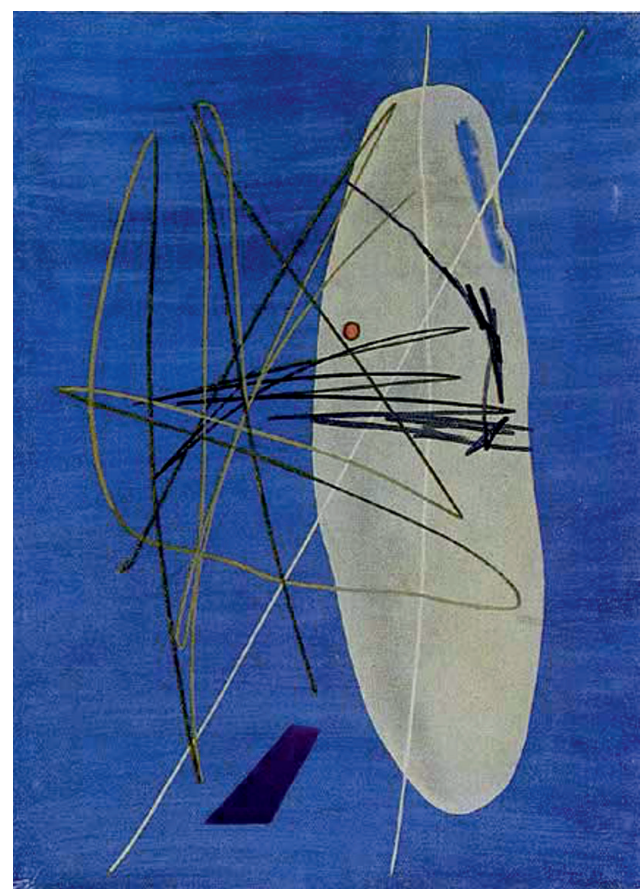

Fig. 2. Hans Hartung, T1934-2, 1934. Óleo sobre lienzo. Fondation Hartung- Bergman, Antibes (obra expuesta en la Galeria Pierre Loeb de París en 1936).

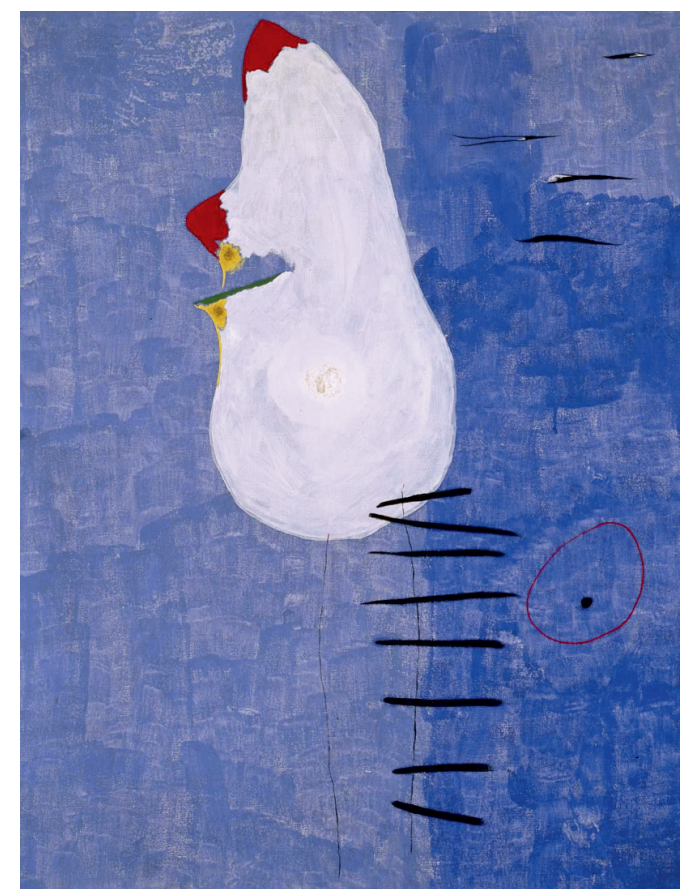

Fig. 3. Joan Miró, Peinture, 1927. Óleo sobre lienzo. Museo Nacional Centro de Arte Reina Sofía. 
Jean Arp y en relación con la abstracción de síntesis de Alberto Giacometti o Jean Hélion. Seguidamente el escultor catalán participó en las principales exposiciones que abordaron el concepto de abstracción como: Thése, antithése, synthése, organizada en 1935 por el pintor suizo, miembro de Abstraction-Création, Hans Erni y por el filósofo Konrad Farner en el Kunstmuseum de Lucerna dirigido por Paul Hilber ${ }^{24}$, con un concepto de abstracción integrador del surrealismo, con la colaboración del Anatole Jakovski y que mostró cuatro importantes obras del catalán ${ }^{25}$. Mientras que Cubism and Abstract Art ${ }^{26}$, de Alfred H. Barr en el Museo de Arte Moderno de Nueva York, en 1936, dio preeminencia a la dependencia del arte abstracto del cubismo. Barr se decantó por las tendencias abstractas del surrealismo, o "abstracción expresionista", como desarrollo de futuro, en el que incluyó a González, junto a Miró, Masson o Picasso, y los más jóvenes Arp, Miró, Hélion, Moore y Giacometti. Esta colectiva que se centró en el arte europeo, ponía de manifiesto la necesidad de defensa de la vanguardia ante el avance de los totalitarismos ${ }^{27}$, al igual que la exposición del Musée du Jeu de Paume del verano de 1937, mostraba por vez primera el desarrollo del arte internacional de vanguardia en Francia, como contrapunto a la exposición de arte francés del Petit Palais ${ }^{28}$. Origines et développement de l'art indépendant, contó con una serie de espacios para enseñar el proceso del arte moderno hasta la no figuración, y el arte más nuevo en el que también se incluyó a Hartung junto a artistas tan diversos como Miró, Hélion, Magnelli, Kupka, Magritte o Penrose, y quiso asociar la obra de González con la de Brancusi ${ }^{29}$, a la vez que sendas esculturas de Picasso y del maestro catalán abrían el recorrido ${ }^{30}$.

En un breve artículo de 1935, el pintor Luis Fernández también trató las dos vías de la abstracción, distinguiendo entre las obras que suprimen la evocación del mundo, refiriéndose a las corrientes concretas y las que amplían su evocación para introducir imágenes síquicas, donde las relaciones con el objeto pueden ser - dice-o meras alusiones o una descripción mucho más exacta $^{31}$. El pintor Jean Hélion, amigo de Hartung desde su llegada a París ${ }^{32}$, se situaba en un punto intermedio, centrándose en la importancia de la construcción de un orden plástico superior en la propia tela, lo que le llevó a primar la estructura como proceso de complejo equilibrio entre los diferentes elementos de la obra ${ }^{33}$, que se resume en su sentencia: "L'art est une façon de penser produisant un fait, et aussi un fait qui est une façon de penser. L'un sans l'autre n'a pas de sens" ${ }^{\prime 3}$.

24 Enri, 1935: 27-28; Anónimo, 1934: 273.

25 Del 24 de febrero al 31 de marzo, se mostraron cuatro obras de González de 1934: Femme se coiffant II, reproducida en el catálogo y Petite Maternité, Danseuse à la palette, y Le rêve/Le baiser (Hilber, 1935: 42 y fig. 36).

Enri, 1935:27-28; y Cahiers d'Art, 1934 (b): 273.

Según Noizet (Noizet, 2011: vol 2: 6) Jakovski quiso una exposición retrospectiva del arte contemporáneo desde sus orígenes hasta sus límites.

26 Contó con dos esculturas de González: La grande trompette, ca 1932-33 y Eblouissement/Personnage debout de 1932, que perteneció a la col. Gallatin (Barr (a), 1936: 211 y 216).

27 La exposición y su catálogo fueron modelo de historia formalista de la vanguardia (Noyes, 1988: 284-295).

${ }^{28}$ Maîtres de l'art independant entre junio y octubre reunía a la escuela de París, con los clasicistas Maillol, Despiau o Derain, los fauves y los cubistas (Krebs, 1997: 493-95). Kandinsky la criticó su seguimiento de los intereses del mercado (Boissel, 1998: p. 93).

${ }^{29}$ En las salas XIV y XV además de González y Hartung se exhibían neoplasticistas, surrealistas, constructivistas y jóvenes abstractos como Hélion, Domela, Ferren o Benno. Un anuncio publicado en la p. 95 del 1-3 de Cahiers d'Art, 1937 indicaba que las obras del González y Brancusi se incluirían con las de los pintores que no pertenecían a una tendencia precisa. Hartung (Hartung, 1976: 115) dice que su pintura estuvo colocada entre una obra de Léger y otra de Miró.

${ }^{30}$ La segunda obra de González en la exposición no ha podido ser identificada. El catálogo describe la presencia a la entrada de Tête de femme en cemento de Picasso y Sculpture en hierro de González. La presencia de las dos obras en lugar tan destacado se debió al impulso de Christian Zervos (Derouet, 2011: 141).

31 Fernández, 1935: 240.

32 Por sus relaciones con USA, Hélion fue determinante para la recepción americana de la pintura de Hartung (Pierre, 2002: 198-207).

${ }^{33}$ Hélion, 1934: 260.

${ }^{34}$ Hélion, 1935: 60 
Julio González en su principal escrito, Picasso et les cathédrales. Picasso sculpteur, de ca. 1931-3235, también trató el concepto de abstracción, y lo primero que hizo fue rechazar la abstracción geométrica o concreta, con el argumento de que impedía la expresión lírica, al declarar: "Efforcez-vous de tracer à la main un cercle parfait — peine inutile—, seules les imperfections montreront votre personnalité", adelantándose a Joan Miró, que en 1936, explicaba que los signos abstractos de su pintura eran una representación concreta de su espíritu y por tanto una realidad ajena a una idea de abstracción desnuda ${ }^{36}$. En segundo lugar, González buscó la invención lingüística que unificaba vista e idea, dando importancia al proceso directo, de una forma próxima a lo que Hélion había llamado la "ocupación completa del cuadro", que el escultor relaciona con la idea de "invención", al mismo tiempo que alude a contenidos surrealistas de expresión de lo humano y de lo misterioso:

"L'artiste moderne entrevoit un monde nouveau qui s'œuvre devant lui”, de modo que "ayant atteint des régions mystérieuses il se sent seul, il tremble, il craint, il se méfie, $\underline{I l}$ cherche! [...] Alors il crée, invente des formes, des plans, des oppositions de plans des perspectives autres, des formes dans l'espace!".

Concluyendo que la geometría en arte solo estaba avalada por la cualidad espiritual del espacio, en un proceso de síntesis geométrica que mantendría el impulso vital de la materia:

"On peut accepter, sur une toile, une certaine déformation d'ordre optique-géométrique [...] cette déformation, résultant d'une synthèse, serait sérieuse en même temps que belle et pourrait de plus, étant purement création psychologique, devenir déformation géométrique, si la réalisation de l'œuvre en fait une nécessité. Si les déformations synthétiques de la matière, de la couleur et de la lumière, les perforations, les manques de plans matériels donnent à l'œuvre un aspect mystérieux, diabolique, fantastique, ici l'artiste, en plus d'idéaliser une matière à laquelle il donne la vie, a affaire en même temps à l'espace qui la divinise".

Aunque el ideario artístico de Julio González fue muy personal presentó concomitancias con el pensamiento defendido en la exposición de Lucerna, que propugnó la incorporación de la vida emotiva a la abstracción, en concordancia con el discurso crítico de Anatole Jakovski, defensor de un arte que uniera pensamiento y sentimiento, forma y contenido, y que superara por la síntesis las dos ramas irreconciliables de la abstracción representadas por Mondrian y Miró ${ }^{37}$. Una nueva vía del arte en la que este crítico situó las obras de González, Hélion, Arp, Giacometti o Brancusi ${ }^{38}$.

El ámbito anglosajón fue especialmente sensible a la recepción de la abstracción con signos de emoción vital. La revista Axis defendió la idea de síntesis como consecuencia de la experiencia de Abstration-Création, con espacio para la difusión de la obra de González en paralelo a la de Miró. En el primer número de esta revista, su editora Myfanwy Evans, define la obra de Julio González como abstracción en el que se mantiene el vestigio del objeto y la de Joan Miró por su sugestión de surrealismo ${ }^{39}$. Y un artículo de Anatole Jakovski, donde describe la escultura del catalán por la profunda expresión de la angustia de lo atávico, preludiada por Kandinsky, era ilustrado con imágenes de Tête dit le pompier, ca. 1933 junto al lienzo de Miró Peinture de 19

35 AIVAM, Fondo Julio González, n. ${ }^{\circ}$ 1816-1837, o también: Tabard, 1999: 125.

${ }^{36}$ En la entrevista de Duthuit (Duthuit:1936: 261), Joan Miró declara: “Avez-vous jamais entendu parler d'une sottise plus considérable que 1' 'abstraction-abstraction'”.

37 "Le carré immémorial de P. Mondrian et le protoplasme du désir-Miró, sont justement les bouts de ces deux branches devenues absolument incontinuables-peintures sommets qui exigent une nouvelle synthèse, l'art d'avenir qui ne séparera plus la pensée du sentiment, le contenu de la forme, c'est l'ère et l'heure de la nouvelle jeunesse qui s'annonce" (Hilber, 1935: 12-13).

38 Noizet (Noizet, 2011: 25) publica unas notas inéditas para la exposición de Lucerna en las Jacovski e desarrolla la tercera vía, la de la síntesis, incluyendo a Hélion, Erni, González,Giacometti, Nicholson, Brancusi, Arp, y Calder.

39 Evans, 1935: 3-4 
de abril de $1933^{40}$. En 1936, cuando esta revista también se interesó por la obra de Hartung, defendió abiertamente una vía considerada más fértil que la de Abstraction-Création, la de la forma abstracta subjetiva en la que se asociaban visión y pensamiento, citando entre otros a Miró, Arp, Kandinsky, Giacometti, Masson y Ernst ${ }^{41}$. Y Herta Wescher se refirió a González y a Joan Miró como dos artistas que buscaban formas nuevas y expresivas, destacando la capacidad del escultor para crear numerosas formas plásticas y fusionarlas en un sólo tema ${ }^{42}$.

La novedad de la escultura de González también fue apreciada en la revista franco-americana de Eugene Jolas, Transition ${ }^{43}$, que en 1934 había publicado un artículo de Carola GiedionWelcker, en el que la obra del español se destacaba por la fuerte atmósfera plástica y por su capacidad de absorber el accidente en la ejecución ${ }^{44}$, y en la que, en 1937, James Johnson Sweeney incluyó a González dentro de un reportaje dedicado también a los escultores Naum Gabo, Ben Nicholson y Henry Moore, y a los pintores Joseph Albers, Alberto Magnelli, Jean Hélion, John Piper, Joan Miró, Wolfrang Paalen, Vassily Kandinsky y Hans Hartung ${ }^{45}$; artistas en cuyas obras o bien se daba una revitalización de la abstracción en base a la expresión automática, o bien, se realizaba una síntesis con dominio de la estructura, espacio abierto y totalizador con sentido de unidad compositiva, como en Hélion o Magnelli.

\section{Hans Hartung en el taller del escultor}

La relación de maestro y alumno entre Julio González y Hans Hartung, pudo afianzar la autoestima del primero, como pensó Pierre Descargues, pero sobre todo sirvió a Hartung para experimentar nuevas técnicas, como el ensamblaje del hierro y para reflexionar plásticamente sobre la línea y el espacio, sobre el ejemplo de la gran inventiva formal de la escultura y el dibujos del español, y en virtud de una afinidad electiva que este mismo crítico resaltó ${ }^{46}$, y que aplicaría también a su pintura. Aunque Hans Hartung poseía una profunda vocación pictórica, la potencia de la obra de González le impulsó a experimentar la forja de una escultura que presentó en 1938 en el Salon des Surindépendants ${ }^{47}$. Sculpture (fig. 4) tenía una factura semejante a la escultura lineal de González, manteniendo el formato vertical que inevitablemente sugería la forma humana, pero sin permitir la referencia figurativa del título. En lugar de basar su linealidad en un proceso doble de análisis formal de la realidad y de síntesis abstracta en la composición como hacía el español, Hartung se centró en la configuración en tres dimensiones y en hierro de la grafía enredada derivada directamente de su pintura de libre improvisación del trazo.

Algunos de los aspectos formales del hierro de Hartung incidían en la rigurosa contemporaneidad, por ejemplo, la escultura está construida a partir de dos elementos que evocan los que compusieron la escultura Boule souspendue (1930-31), de Alberto Giacometti, en la que una forma esférica y otra oval con filo convexo y en movimiento, podían sugerir aspectos inconscientes del comportamiento humano ${ }^{48}$. Sculpture tiene también una fuerte relación con varios dibujos de proyectos escultóricos de González como: Personnage à la grand boule (1937), Per-

\footnotetext{
$40 \mathrm{Su}$ artículo es un repaso por la obra de Mondrian, Malevich, Kandinsky, Miró, Brancusi, González, Giacometti, Hélion y Nicholson (Jakovski, 1935: 14-21).

41 Thwaites, 1936: 21-25

42 Wescher, 1935: 28-29.

43 Fundada en 1927 por el poeta Eugene Jolas y su mujer Maria MacDonald, Sweeney fue su editor de junio de 1936 a mayo de 1938 .

${ }^{44}$ Giedion-Welcker, 1934-35: 199.

45 Transition, 1937, n. ${ }^{\circ} 26$, pp. 91.

46 Descargues, escribe (Descargues, 2001-2002: 50): “[...] alrededor de las varillas de hierro que alzaba González, [...] que eran dibujos en el espacio, y de los trazos que Hartung acababa de intentar en su soledad de Menorca y que proponía como signos de vida sobre un cuadro había profundas afinidades".

47 "Le Salon des Surindépendants". En Beaux-Arts, 14 octubre de 1938.

48 Dalí, 1931: 16.
} 


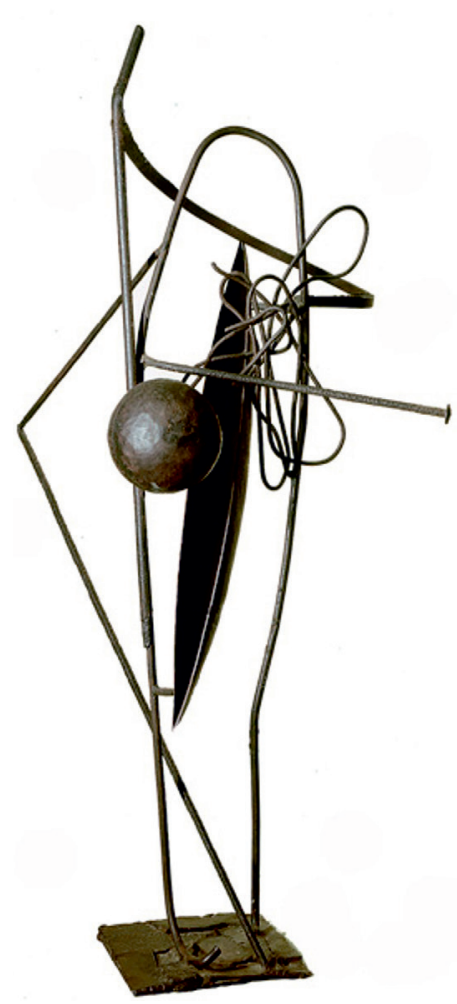

Fig. 4. Hans Hartung, Sculpture, 1938. Hierro forjado (Pieza única). Fondation Hartung-Bergman, Antibes.

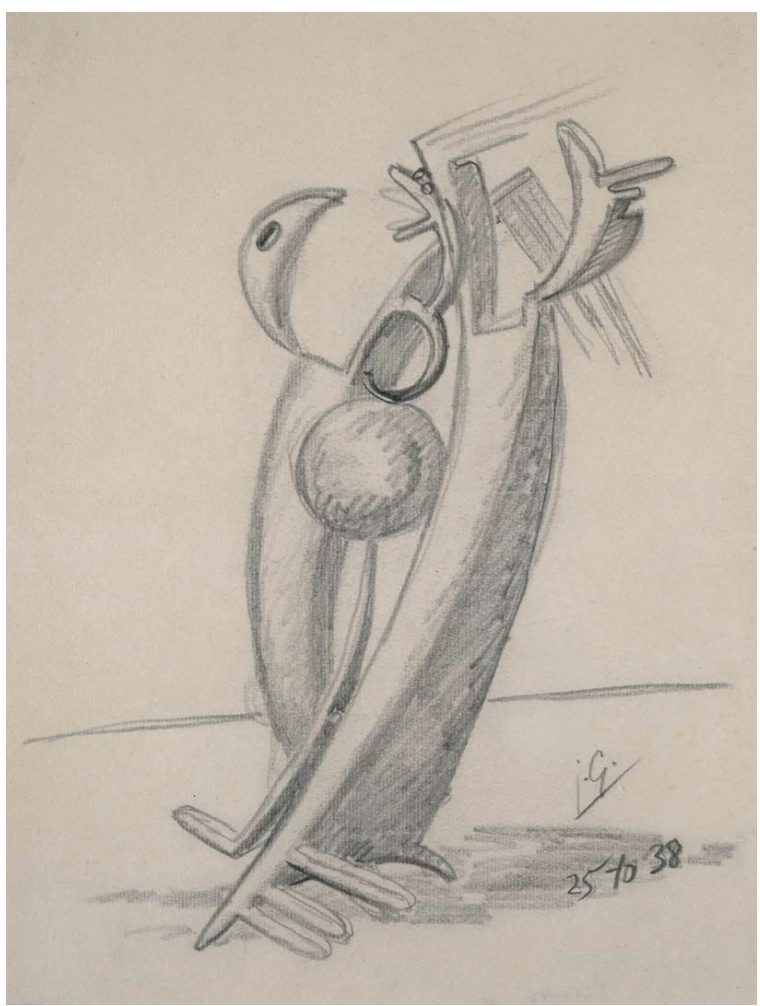

Fig. 5. Julio González, Personnage oiseau, 1938. Grafito sobre papel, Museo Nacional Centro de Arte Reina Sofía; Madrid.

sonnage oiseau (1938) (fig. 5), o Construction à la boule de 1940, en los que la forma esférica y la curva cóncava acogiéndola, aparecen integradas en una derivación formal antropomórfica, donde la esfera centra la composición como elemento turbador. Otros elementos de la escultura de Hartung, especialmente su grafía expresiva, avanzaban aspectos de su plástica de postguerra, y es interesante mencionar que esta escultura ilustró un texto de Georges L. K. Morris, en la neoyorquina Partisan Review, en la que también escribía Clement Greenberg ${ }^{49}$.

El hierro de Hartung ha sido considerado como un anticipo del arte que este escritor americano iba a defender en los años de postguerra ${ }^{50}$, cuando, por ejemplo, definió la nueva escultura como aquella en la que: "el espacio se divide, se encierra y se conforma pero no se llena" 51 , es decir una escultura sin bloque y abstracta, que Greenberg vinculó a la obra de David Smith. En comparación con lo que estaba haciendo este escultor norteamericano, la gran diferencia está en el linealismo de la obra de Hartung, inspirado en la escultura de González de los años 1934-35, frente a la fuerte conciencia de volumen cubista de la obra de Smith como Vertical Structure de

49 Morris, 1939: 31-33. En ese mismo número de Partisan Review Clement Greenberg publicó "Avant-Garde and Kitsch". Desde 1937, Georges L.K. Morris fue crítico de arte de la renovada Partisan Review, participando financieramente hasta 1943. Morris, graduado por Yale, estudió arte con John Sloan en la Art Student League de Nueva York y en París con Fernand Léger y Amédée Ozenfrant. Amigo de Albert Eugene Gallatin y de Jean Hélión, en 1937 fue coeditor con el primero de la revista Plastique. Sobre L.K. Morris: Lorenz, 1981.

50 Abadie, 1992: 2, menciona a Greenberg y a Pollock, además de indicar que la obra respondía a un concepto entre el cubismo y el expresionismo.

${ }^{51}$ Greenberg, 1961: 132-37. 
1939, que tendría que ver con piezas de González como Femme se coiffant III de ca. 1936, las tres versiones de Femme assise I-III (1935-36) que llevan a Figure abstraite de 1942.

El desbordamiento expresivo pre-informalista de la línea en la escultura de Hartung fue consecuencia de su voluntad personal de imponer la emoción inconsciente al trazo, y como en su pintura, conseguir las cualidades plásticas en base a un cierto automatismo primitivo que no solo era de raíz surrealista ${ }^{52}$. En este sentido, George L. K. Morris se refirió a la escultura de Hartung como un ejemplo de sensibilidad caligráfica, acorde con su pintura, que interpretó como un novedoso resurgir de la sabia vital del cubismo en contraposición a la frialdad constructivista ${ }^{53}$. Sculpture, que posee un aspecto de altorrelieve, expresa el resquicio de vida que permanece en toda la obra del pintor haciendo considerar a J. J. Sweeney que la pintura de Hartung:

\begin{abstract}
"Malgré tout... n’est jamais strictement abstraite ni expression géométrique. En fait, contraire à toute visible évidence, pour la plus grande part, elle semble rarement non-figurative. Il y a une telle vie dans les signes abstraits employés qu'ils semblent constamment être sur le point d'arriver à quelque chose que nous avons connu. Ils produisent un effet comme s'ils étaient vraiment une sensation d'une accablante métaphore" ${ }^{54}$.
\end{abstract}

La originalidad de la escultura madura de Julio González, en su forma y en su realización material, enriquece sus significados si se hace una correspondencia con una parte de la pintura coetánea. La escultura lineal de la primera mitad de la década, con obras como Petite tête au triangle (1933) o Grand maternité (1934), estaba configurada como un dibujo tridimensional de varillas de hierro de línea fina que responde a un intenso proceso de depuración cercano al concepto plástico de ruptura y "asesinato de la pintura" inspirador de las originales obras a base de líneas y elementos aislados de color sobre papel Ingres que Joan Miró realizó en 1931, en las que el fondo pictórico aparece significativamente vaciado ${ }^{55}$. La escultura que inició en 1935, con la serie de Femme assise, y continuó con obras como Personnage allongé, ca. 1936 y Homme et Madame Cactus (1938-40), en las que la sensación de gravedad se conseguía a través de chapas de perfiles ortogonales, ofreció un parentesco formal con la pintura de volúmenes geométricos y espacios totalizados de Alberto Magnelli ${ }^{56}$ y de Jean Hélion, con los que González expuso en el verano de 1935 en la salle d'Art Castelucho- Diana, y donde también se mostró una de las geometrizantes figuras en escayola de la serie Tête-crane de Giacometti. La obra final, conclusiva, de Julio González está compuesta principalmente por dibujos, muchos de ellos coloreados, que dejaron de ser proyectos escultóricos, o post scriptum relacionados con esculturas definitivas, para convertirse, en un diario dibujado con sus invenciones abstractas, abrumadoras, fantásticas y desgarradoras, reflejando un ánimo profundamente afectado (fig. 6). Dibujos a base de planos estructurados, delineados con esmerado detallismo, en los que el escultor optó por una ocupación regulada de la superficie pictórica que encajaba en la idea de orden plástico superior de Jean Hélion, y que por sus cualidades estructurales y por su preocupación por el color conectaban con la obra de Hartung (fig. 7) ${ }^{57}$.

${ }_{52} \mathrm{Al}$ inconsciente formal de la línea curva como constante en la Historia del Arte, se refirió André Lothe en un artículo que se publicó en el número de la revista franco-americana editada por Sweeney, en el que figuraban las obras de González y Hartung (Lothe, 1937: s/p.)

${ }_{53}$ Hartung incorporates a sensitive calligraphic ease in both painting and sculpture, which has brought back the 'touch' that had been the life-blood of Cubism (Morris, 1939: 33).

54 Sweeney, 1949: 3.

55 Todas las ilustraciones de Miró que Zervos incluyó en su artículo de 1931 (Zervos, 1931) son de este tipo de pinturas, que representan personajes femeninos, y que representa el momento más radical y abstracto de su producción, entre 1928 y 1931.

56 González había visitado una exposición de Magnelli en la Galería Pierre con obra de la serie de "piedras", en las que la idea de volumen y de abstracción inspira o confluye con las búsquedas de González, la exposición se tituló Euvres récentes de Magnelli, 1-14 de junio 1934. Según la viuda de Magnelli González visitó en varias ocasiones el taller del pintor y hay datos que avalan que la relación continuaba en 1938 (Leal et al., 2007: 316).

57 Gran parte de la colección de dibujos de González, que Hartung conservó toda su vida, eran de este tipo. El pintor tuvo una magnífica colección que guardaba en su estudio junto a sus propias obras. 


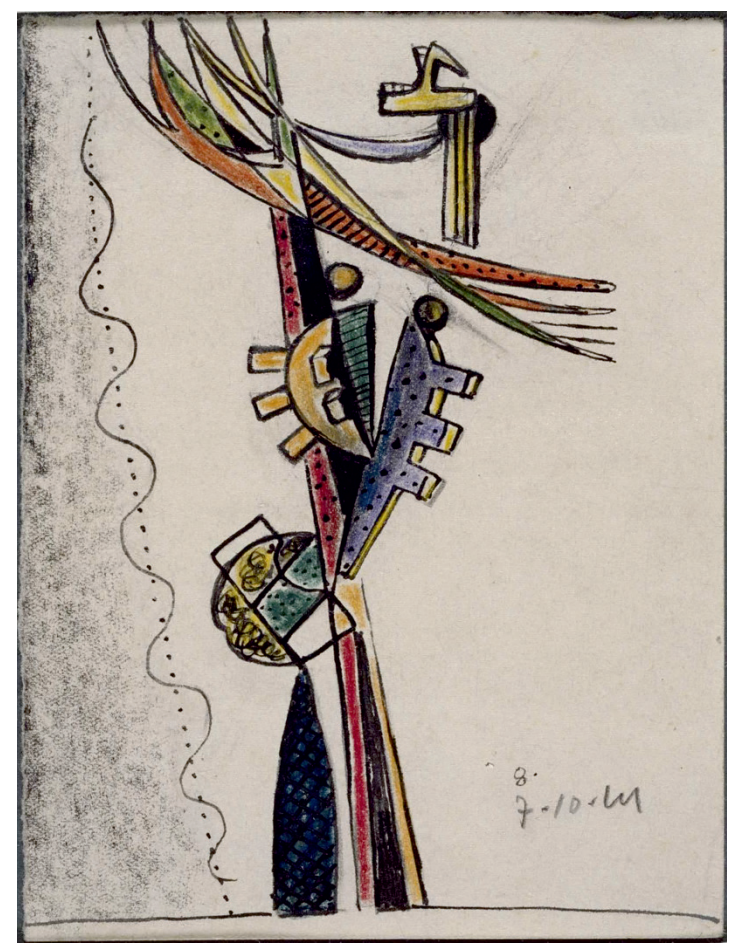

Fig. 6. Julio González, Personnage à la ligne sineueuse, 7 octubre 1941, Lápiz, lápiz color, tinta y pluma sobre papel. Museo Nacional Centro de Arte Reina Sofía, Madrid.

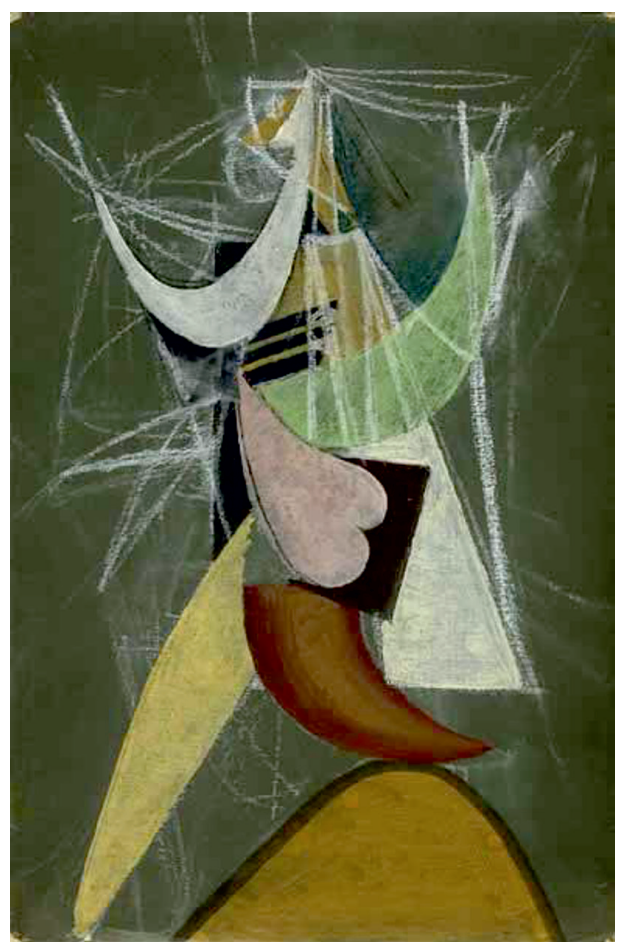

Fig.7. Hans Hartung, Sin título, 1940, Óleo y papel sobre papel. Fondation HartungBergman, Antibes.

Cuando acabada la guerra, Hans Hartung despertó el interés de la nueva crítica francesa, el pintor vivía rodeado de las obras de González y de las que él mismo produjo en sus años de convivencia con el escultor. Madelaine Rousseau, que en 1949 publicó una importante monografía con prólogo de Sweeney ${ }^{58}$ y que describió su pintura en Cahiers d'Art como "un langage violent, jaillissement direct d'une émotion dont la spontanéité était contrôlée, dominée par des exigences plastiques", le visitó en 1945 en el taller de Arcueil que había pertenecido a González y se encontró a un artista resuelto a mirar adelante: "Sans s'attarder au pénible souvenir de ces années passées - escribió-. Il regardait vers l'avenir avec courage et optimisme. Des toiles nouvelles voisinaient, dans l'atelier, avec les derniers dessins de 1939 qu'il utilisait pour renouer le fil rompu depuis six années" 59 . Rousseau, demostrando la brecha de la nueva crítica, pensaba que en los años treinta se habló poco del arte abstracto en Francia, aunque situó la pintura de Hartung entre la expresión de los surrealistas abstractos y la geometría constructiva ${ }^{60}$, al mismo tiempo que destacaba la importancia para su pintura de su violentos gouaches y dibujos realizados en 1939, cuando mayor fue su cercanía al escultor.

Para llegar a la pintura compacta y autónoma de postguerra, Hans Hartung hubo de hacer un recorrido de profunda transformación, partiendo de una pintura abstracta que, recordemos, Swee-

58 Citado en bibliografía. Sweeney (1949). La importancia de este libro para el lanzamiento de la pintura de Hartung en la postguerra se aprecia si consideramos que el segundo número de la colección se dedicó a Joan Miró, cuya carrera se relanzaría en los cincuenta, como sabemos.

59 Rousseau, 1949: 317.

${ }^{60}$ En concreto la describe por: "Le caractère dramatique, lyrique de cette peinture me frappa par son contraste avec la géométrie des constructivistes autant qu'avec les épanchements incontrôlés des néo-surrealistes abstraits”. 
ney definió como una metáfora abrumadora con presencia del signo vital. Una obra que en 1936, Myfanwy Evans había situado entre la de los artistas que no "se sometían a otros" y que, o bien tenían el surrealismo como incidental, o practicaban una abstracción vital, como Picasso, Arp, Giacometti, Moore, Miró o Piper, etc ${ }^{61}$. Y una pintura que, en 1941, George L.K. Morris, editor de Partisan Review, puso en paralelo con la de Julio González, como ejemplo de obra independiente de la Francia no ocupada ${ }^{62}$; cuando artistas, como Klee, Miró y González, se mantenían en concepciones abstractas en las que la significación naturalista también jugaba un importante papel $^{63}$.

La pintura de Miró fue el primer estímulo de novedad en la obra de Hartung, en el momento en que se desvinculó de las formas reconocibles, durante el período de trabajo y reflexión en Menorca. Tuvo acceso a la revista Cahiers d'Art, donde pudo seguir la evolución de artistas de su interés como Kandinsky o Klee ${ }^{64}$, y donde en 1934, su amigo el crítico Will Grohmann publicó un artículo en alemán, en el que definía la pintura de Joan Miró como una obra esencialmente equilibrada a pesar de estar ligada al automatismo, y como una pintura concreta en el detalle y abstracta en su conjunto ${ }^{65}$. Pierre Daix, que relacionó la pintura de Hartung con la capacidad de sueño y la claridad compositiva de Joan Miró, se refirió también a la presencia de una extraña disparidad en los trazos, asegurando, por ejemplo que como la pintura T-1933-14 "apporte des contrastes jamáis explorés entre le dessin linéaire, le dessin en écheveau, le dessin en mouvement brownien, le dessin bouillé et la foudre du trait" 66 .

Frente la pintura de los años menorquines, con lienzos que revelaban un sentido del equilibrio compositivo arraigado en el artista, y la libertad en el grafismo y en el color que Jean Hélion valoró ${ }^{67}$, la obra de los primeros años de Hans Hartung en París, fue expresando una progresiva tendencia hacia trazos gruesos combinados con planos de color que desembocan en los expresivos dibujos abstractos de 1939, coincidiendo con el inicio de su relación con González. En los años inmediatos al inicio de la guerra Hartung logró una moderada repercusión pública. Participó en una colectiva en la Galerie Pierre Loeb, celebrada en mayo de 1936, donde expuso el lienzo T-1934-2, de1934 (fig. 2), que se relacionaba armónicamente con las otras obras expuestas: la escultura biomorfica de Arp, una de las cabezas-cubo de Giacometti, o las formas sintéticas y líricas de la pintura de Jean Hélion, John Ferren y el Kandinsky del período parisino ${ }^{68}$. La exposición supuso la incursión del artista en el ámbito de recepción de una abstracción expresiva descrita en el capítulo anterior, en la que se situó también el decidido interés por el arte abstrac-

61 "The battle has been pitched between abstract painting and sculpture and surrealist painting and sculpture and painting and sculpture; but there it cannot flourish. It is a silly battle. There are too many painters who do no paint in the name of either. Painters who were distinguished... as primarily interested in painting. Their surrealism is incidental, their abstraction a sign of life, not sterility". Evans, 1936:8.

62 Georges L. K. Morris, incluyó la doble ilustración con las obras de Hartung y González, a continuación de su artículo de 1941 en Partisan Review, donde defendió una abstracción independiente de los acontecimientos sociales y basada en la idea de orden estructural. Morris, 1941: 406-13 y Lorenz, 1981: 76-78.

63 "I only say that what abstract art can offer is something different and something particularly pertinent to our time (...), a few on the border - line (Klee, Miró, González) have remained rooted in the abstract conception, with the naturalistic over-meaning playing a small part through the best of their work" (Morris, 1941: 414).

${ }^{64}$ Carta en alemán de Hans Hartung a Will Grohmann de 29 de octubre de 1934, Archive Fondation HartungBergman, Antibes (AFHB), en la que se dice, en traducción no literal: "Dans le dernière moitié des Cahiers d'Art, il semble que les allemands ont pris d'assaut Paris. Peut-être que les circonstances étaient bonnes pour que l'on attache tout d'un coup de l'importance et du sens à quelques-uns de nos peintres, dont l'influence restau jusqu'ici très limitée. J'ai peur que nous devions nous soumettre à cette dénomination de 'Groupe des Jeunes' Que font par ailleurs les jeunes abstraits comme Winter, Kuhn et les autres? Je pensais qu'il serait impossible de fonder un groupe artistique". Hartung parece referirse al volumen 1-4 de 1934 de la revista, que además de incluir un monográfico dedicado a Miró (Cahiers d'Art, 1934 (a):11-58) publicaba en las páginas finales, sendos artículos dedicados a Kandinsky, Max Ernst y Klee.

65 Grohmann, 1934: 38.

${ }^{66}$ Daix, 1985: s/p.

${ }^{67}$ Lettre de Jean Hélion à Véronique Moret-Mummenthey citado por: Claustres, 2005: 173.

68 Titulada: Des euvres récentes de Arp, Ferren, Giacometti, Hartung, Hélion, Kandinsky, Nelson, Paalen, Taueber-Arp, La Galerie Pierre, fue objeto de la publicación de un cataloguito sin año. Galeria Pierre, [1936]. 
to más novedoso de Albert Eugene Gallatin ${ }^{69}$, que compró obra de Hartung en $1938^{70}$, tras haber adquirido también obra de Julio González en $1935^{71}$. En su etapa londinense, Peggy Guggenheim, contó con el pintor alemán para dos exposiciones de su galería Guggenheim Jeune, como fueron, en noviembre de 1938, la amplia colectiva, Exhibition of Collages, Papiers-Collés and PhotoMontages, que instaló con la participación de Roland Penrose, donde Hartung mostró la faceta de su arte más relacionada con algunos collages de Magnelli, y en la tradición de Miró. Y por último, en mayo de 1939, la muestra organizada por Herbert Read: Exhibition of Abstract and Concrete Art, con presencia de artistas situados en las dos ramas de la abstracción ${ }^{72}$. Mientras que en París, Hartung se encontraba con una significativa resistencia a su participación en el Primer Salon de Réalites Nouvelles de 1939, que organizaron con un concepto más restrictivo, los Delaunay y Nelly Van Doesburg.

Entre 1938 y 1942, los últimos años de vida de González, el trabajo artístico de Hartung se hallaba en un proceso de búsqueda notable, en un período marcado también por la primera fase de la guerra en Francia y su participación directa entre diciembre de 1939 y octubre de 1940 en la legión extranjera, que supuso asumir, en este caso de forma trágicamente práctica, la aversión al fascismo que el escultor catalán y su familia también vivieron en los años de la Guerra Civil española. En ese período convulso, junto a la forja del hierro y su principal medio de investigación plástica como fueron los dibujos a gouache, pastel o grafito, Hartung trabajó también la pintura en diferentes soportes y texturas y se interesó por el collage. Sus bocetos y dibujos coloreados demuestran interés por el trazo libre y los planos estructurados, junto a la investigación de la figura humana, especialmente de los componentes expresivos del rostro, en la serie de cabezas de 1940 y 1941 que derivan de los estudios de figuras de formas óseas de Picasso del final de los años veinte y las cabezas de Montserrat gritando de 1939 a 1941 de González. Mientras que en otros estudios más personales, realizados a tinta y lápiz entre 1941 y 1945, Hartung se concentró en la composición estructurada y ortogonal basada en el trazo libre con detalles levemente figurativos. En cuanto a su pintura, desde obras como T. 1936-1, el lienzo adquirido por Albert Eugene Gallatin en 193873, a la obra expuesta en 1937 en el Jeu de Paume, T. 1936-14, 1936, y una pintura tan expresionista como T.1938-11, 1938 (fig. 8), se constata una evolución en la que, sin abandonar el gusto por la línea, tiende a los planos expresivos y estructurados que claramente tienen en mente un concepto espacial cubista compatible con González.

Pinturas con una estructura compositiva más totalizadora y abstracta, en un ambiente proclive a una expresión menos lírica y más rotunda. Obras que revelan como la intuición plástica del pintor le llevó a aislar las estructuras expresivas de los perfiles de hierro de la escultura de González y de los planos de sus dibujos de figuras fantásticas, y aplicarlas a su pintura, que en su madurez ofreció un predominio de la emanación directa del trazo profundo, pesado y negro, como único y estructural sustento de la composición. En la cercanía con la obra del escultor español Hans Hartung se reafirmó en algunas de sus prácticas, como la del concepto del dibujo como campo de experimentación plástico y fue capaz de identificar la faceta de expresión del

\footnotetext{
${ }^{69}$ Albert Eugéne Gallatin inauguró la Gallery of Living Art en la University of New York, Washington Square East, en diciembre de 1927, y en torno a 1936 cambió la denominación a Museo. Entre 1933-38, se centró en adquirir abstracción con obras con la colaboración de Hélion, comprando obras de Mondrian, Arp, González, Hartung, Magnelli. Las obras pasaron en 1943 al Museo de Filadelfia.

70 Gallatin visitó al pintor en el verano de 1938 (Stavitsky: vol. 2, 377-378, y vol. 7, 116).

71 Se conservan sendas cartas de Gallatin al escultor fechadas en 16 de agosto y 24 de agosto de 1935, de las que se infiere que la adquisición de la escultura en plata, por cuyo título pregunta el americano en la segunda de sus misivas, se produjo en ese tiempo (AIVAM Fondo Julio González, n. ${ }^{\circ} 1855$ y 1856).

72 De acuerdo con su título la exposición fue bastante heterogénea, con artistas como: Arp, Calder, Gabo, Hélion, Hepworth, Magnelli, Mondrian, Nicholson, Van Doesburg, Taeuber-Arp, o Vantongerloo, entre otros. Read/ Lecomte/ Scutenaire, 1939.

${ }^{73}$ La versión de mayor dimensión que actualmente conserva el Musée Georges Pompidou figuró en la muestra celebrada, en julio de 1938, en New Burlington Galleries, en apoyo al arte perseguido por el régimen alemán, titulada "Exhibition of 20th Century German Art", y fue reproducido en las revistas Axis y Transition.
} 


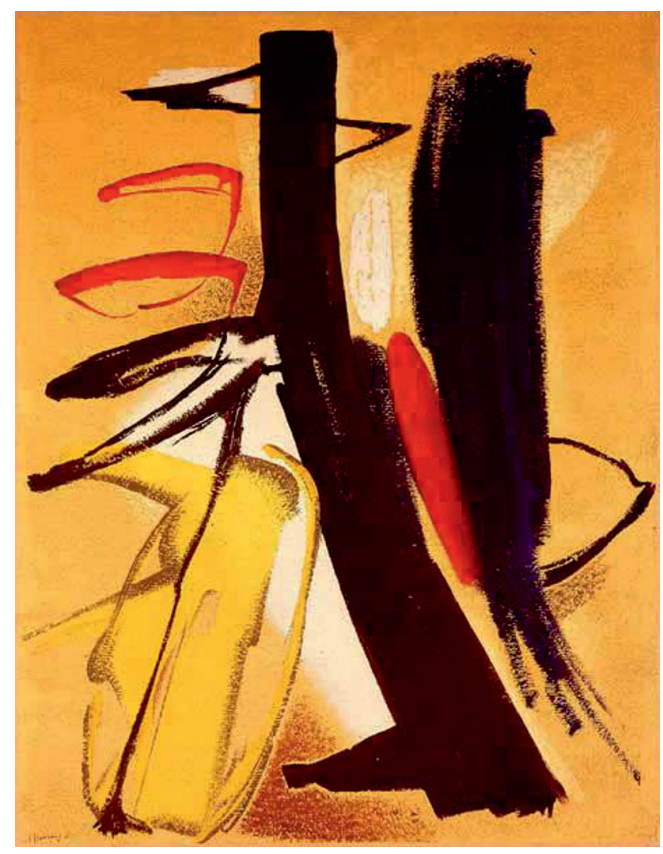

Fig. 8. Hans Hartung, T-1938-11. 1938. Óleo sobre lienzo. Fondation Hartung- Bergman, Antibes.

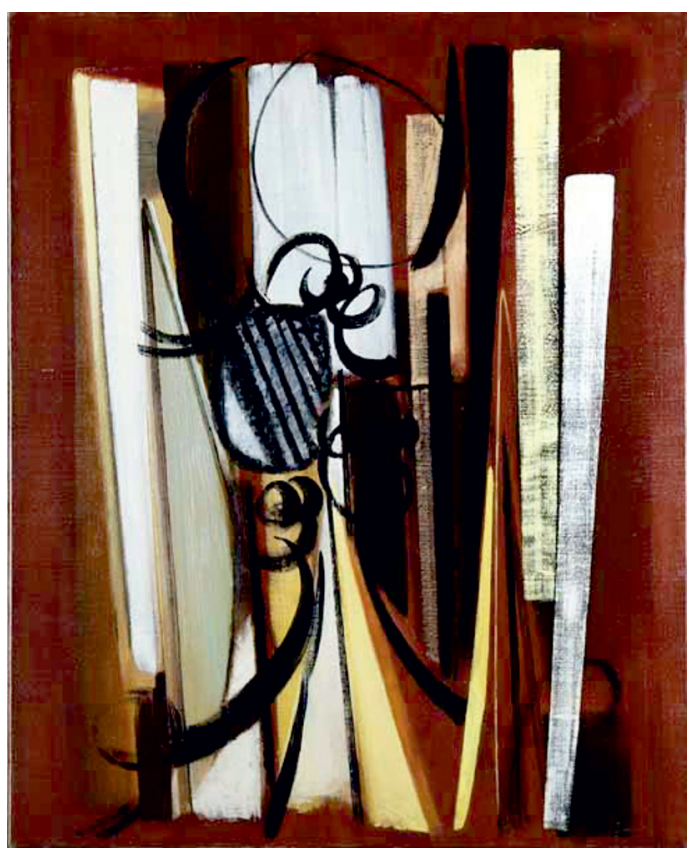

Fig. 9. Hans Hartung, Sans titre, 1945. Óleo sobre lienzo. Fondation Hartung- Bergman, Antibes.

dolor de las figuras surrealistas y abstractas del último González, que como escribió Jakovski, encerraban el espacio transformándolo en "noche" como expresión de lo atávico ${ }^{74}$.

Tras su divorcio de Roberta González, Hartung conservó una colección de obras de Julio González centrada en sus últimas esculturas y los dibujo de 1939 a 1942, que le acompañaron toda su vida ${ }^{75}$. El pintor que defendió el origen del arte abstracto en Cézanne, encontró en González, uno de los artistas que mejor comprendieron el espacio cubista, la inspiración para su propio camino de arte expresivo y estructurado con significación humanista. Una pintura madura que está preludiada en pinturas como Sans titre de 1945 (fig. 9), donde es posible apreciar conceptos arraigados como la estructuración del espacio, la búsqueda intencionada del gesto vital y la armonía de color.

Pionero del informalismo en Francia, Hartung obtuvo el reconocimiento de la nueva crítica de su país desde el final de la guerra, con una pintura que había edificado con gran coherencia en los años de la contienda y en convivencia con González y sus obras. Sus declaraciones de fecha tan temprana como 1946, demuestran también que su pensamiento artístico se basó en el rico debate sobre la abstracción en los años treinta que hemos descrito aquí, declarando:

“Il s'agit d'un état émotionnel qui me pousse à tracer, à créer certaines formes afin d'essayer de transmettre et de provoquer une émotion semblable chez le spectateur. Et puis, cela me fait plaisir d'agir sur la toile. C'est cette envie qui me pousse: l'envie de laisser la trace de mon geste sur la toile, sur le papier, Il s'agit de l'art de peindre, de dessine, de griffer, de gratter'76.

74 Jakovski escribe (Jakovski, 1934: 209): “Quand González enferme l'espace assassinant la lumière, il n’y a jamais d'ombre, c'est toujours de la nuit".

75 Christie's, 1999.

76 Declaración recogida por Charles Estienne en 1946, citada por Daix, 1991. Recogido en: Daix, Pierre y Ayala, Roselyn de: Pierre Daix París des Arts 1930-1950. París: Grand Palais, p. 210. 
La obra de Julio González basada en un concepto de abstracción como expresión de lo vital o abstracción de síntesis y unida a una práctica constructiva a base de planos, proporcionaron al pintor Hans Hartung, en los años que definía su propio arte, unos instrumentos plásticos basados en el trazo como traducción del plano, en la expresión de un profundo sentimiento humano y en una meditada gestualidad en la ejecución, con los que unir sentimiento y pensamiento como base de su obra. Una pintura abstracta subjetiva que puso el acento en la expresión emocional del trazo, como se aprecia en las pinturas abstractas de 1942-45 (fig. 9), que fue preludio de una obra de éxito con la que consiguió prestigiosos reconocimientos como el Gran Premio en la Bienal de Venecia de 1960.

\section{BIBLIOGRAFÍA}

Abadie, Daniel (1992): Une rencontré: Hans Hartung et Julio González 1935-1952. París: Galerie de France/Lugano: Galleria Pieter Coray, Lugano.

Arp, Jean (1931): “Réponse à une enquête sur l'art abstrait”. En: Cahiers d'Art, 7-8, París, 1931, p.357.

Barr Jr., Alfred H. (1936a): Cubism and Abstract Art. Nueva York: The Museum of Modern Art.

Barr Jr. Alfred H. (ed) (1936b): Fantastic Art, Dada, Surrealism. Nueva York: The Museum of Modern Art.

Boissel, Jessica (1998): Kandinsky-Albers. Une correspondance des années trente. París: Les cahiers du Musée National d'Art Moderne, Hors-série/Archives, Centre Georges Pompidou.

Brenson, Michael (2011): "El momento escultórico". En: Julio González David Smith, un diálogo sobre la escultura. Valencia: Instituto Valenciano de Arte Moderno, pp.71-99.

Brzekowski, Jan (1934): "Les Quatre Noms. Hans Arp, Ghika, Jean Hélion, S.H. Taeuber-Arp”. En: Cahiers d'Art, 5-8, París, pp.197-200.

Cahiers d'Art (1934a): "La jeune peinture”. En: Cahiers d'Art, 1-4, París, pp.11-58.

Cahiers d'Art. (1934b): "Les Expositions. Thèse, Antithèse, Synthèse, Kunstmuseum de Lucerne". En: Cahiers d'Art, 9-10, París, p.273.

Christie's (1999): Works by Julio González and other artists from the Fondation Hartung. Londres: Christie's, 30 junio.

Claustres, Annie (2005): Hans Hartung. Les aléas d'une réception. [Dijon]: Les presses du reel, 2005.

Claustres, Annie (2006): "Hans Hartung Clandestine Artist, 1937-1942: the Decisive Years". En: Pontégnie, Anne (ed.): (2006): Hartung 10 Perspectives. Antibes: Fondation Hartung-Bergman/ Milán: 5 Continents Editions, pp. $54-73$.

Curtis, Penelope (2000): "Restaurar el tema: Julio González y la construcción del significado”. En: Kalías. Revista de Arte, 23-24, Valencia, pp. 72-85.

Daix, Pierre (1985): "La trajectoire de Hans Hartung”. En: Hans Hartung. París: Galerie Daniel Gervis.

Daix, Pierre (1991): Hans Hartung. París: Editions de Grenelle, Daniel Gervis.

Dalí, Salvador (1931): “Objets surréalistes”. En: Le Surréalisme au service de la révolution, 3, diciembre, París, pp.16-17.

Derouet, Christian (2006): Cahiers d'Art. Musée Zervos à Vézelay. París: Hazan, Conseil Général de Lyone.

Derouet, Chistian: Zervos et Cahiers d'art, París: Musée National Centre Georges Pompidou, 2011.

Descargues, Pierre: “Julio González”. En: Kalias Revista de Arte, 25-6, Valencia 2001-2002, pp. 44-52.

Duthuit, Georges (1936): “Oú allez-vous Miró”. En: Cahiers d’Art, 8-10, París, 1936, pp. 261-266.

Enri, Hans (1935): “The Lucerne Exhibition”. En: Axis, 2, abril, Londres, pp. 27-28.

Evans, Myfanwy (1935): “Dead or Alive”. En: Axis, 1, enero, Londres, pp. 3-4.

Evans, Myfanwy (1936): “Order, order!”. En: Axis, 6, verano, Londres, pp. 4-8.

Fernández, Louis (1935): “Art sur-descriptif et art non figurative”. En: Cahiers d'Art, 7-10, París. p. 240.

Fernández Aparicio (2008): "Julio González, primer maestro del soplete, en torno a la visión de David Smith". En: Doñate, Mercè (ed.): Julio González, retrospectiva. Barcelona: Museu Nacional d'Art de Catalunya, Madrid: Museo Nacional Centro de Arte Reina Sofía, pp. 127-145.

Fernández Aparicio (2011): "Nueva escultura y visión poética”. En: Yvars, J.F (ed.): Julio González David Smith un diálogo sobre la escultura. Valencia: Institut Valencià d'Art Moderne, pp. 115-147.

Galeria Pierre (1936): Des cuvres récentes de: Arp, Ferren, Giacometti, Hartung, Hélion, Kandinsky, Nelson, Paalen, Taueber-Arp. París: La Galerie Pierre, París.

Greenberg, Clement (1948-58): "New sculpture". Greenberg, Clement (1961): En: Art and Culture Critical Essays, Boston, Beacon Press, 1961. Castellano: Geenberg, Clement (1979) Arte y Cultura. Ensayos críticos. Barcelona: Gustavo Gili, pp. 132-137.

Grohmann, Will (1934): “Von Abstrakten Realismus Zur Realen Abstraktion (Zu Mirós Bilden)”. En: Cahiers d'Art, 1-4, París p. 38.

Hartung, Hans (1976): Autoportrait. Récit recueilli par Monique Lefevre. París: Bernard Grasse.

Hélion, Jean (1934): “La réalité dans la peinture à propos de l'exposition du musée de l'Orangerie". En: Cahiers d'Art, 9-10, París, p. 260. 
Hélion, Jean (1935): Réponse à une enquête sur l'art d'aujourd'hui et ses valeurs plastiques. En: Cahiers d'Art, 1-4, París, p. 60.

Hilber, Paul/ Giedion, Sigfried./ Hélion, Jean/ Jakovski, Anatole/ Kandinsky, Vasili y Sweeney, James Johnson (1935): Thèse, antithèse, synthèse, Arp, Braque, Calder, Chirico, Derain, Erni, Ernst, Fernández, Giacometti, González, Gris, Hélion, Kandinsky, Klee, Léger, Miró, Mondrian, Nicholson, Paalen, Ozenfant, Picasso, Täuber-Ar. Lucerna: Kunstmuseum Luzern.

Hugnet, Georges (1931): “Joan Miró ou l'enfance de l'art”. En: Cahiers d'Art, 7-8, París, pp. 335-340.

Jakovski, Anatole (1934): “Julio González, Galerie Percier”. En: Cahiers d’Art, 5-8, París, p. 209.

Jakovski, Anatole (1935): "Inscriptions under Pictures". En: Axis, 1, enero, Londres, pp. 13-23.

González, Julio (1935): "Réponse à une enquête sur l'art d'aujourd'hui et ses valeurs plastiques”. En: Cahiers d'Art, 1-4, París, pp. 32-33.

Giedion-Welcker, Carola (1934-35): "New Roads in Modern Sculpture”. En: Transition, 23, París, p.199.

Jeffet, William (1994): “Arp, González y Miró. Tres definiciones de la vanguardia contemporánea”. En: Kalías. Revista de Arte, 13, Valencia, pp. 126-135.

Koidl, Nina (2005): “Tensión entre figuración y abstracción: La relación de Julio González con Hans Hartung”. En: Goya. Revista de Arte, 307-8, julio-octubre, Madrid, pp. 295-301.

Krebs, Sophie(1997): “1937, L'art 'indépendant’ à Paris”. En: Les Annés 30 en Europe. Les temps menaçant, 1929-1939, París: Musée d'Art Moderne de la Ville de París, Flammarion, pp. 493-95.

Leal, Brigitte et al. (2007): Julio González, Collection. París: Centre Pompidou /Musée National d'Art Moderne.

Lorenz, Melinda A. (1981): George L.K. Morris. Artist and Critic, Michigan: UMI Reseach Press, Ann Arbor, 1981.

Lothe, André (1937): “The Unconscious in Art". En: Transition. A quarterly review, 26, Nueva York, Londres, París, pp. 82-96.

McCoy, Garnett (ed) (1973): David Smith. Documentary Monographs in Modern Art. Nueva York: Praeger, 1973.

Merkert, Jörn (1992): "Sutiles amasijos de hierro o los riesgos de la experiencia individual". En: Kalias. Revista de arte, 7, Valencia, pp.49-57.

Moret-Mummenthey, Véronique (1985): Hans Hartung. Catalogue sommaire des œuvres 1921-1939, Mémoire de Maîtrise d'Histoire de l'Art, Sorbonne París IV, 1985.

Morris, Georges L. K. (1939): “Art Chronicle. Recent Tendencies in Europe”. En: Partisan Review, vol. VI, 6, Nueva York, pp 31-33.

Morris, Georges L. K. (1941): "In the Mechanical of Abstract Art". En: Partisan Review, Septiembre-Octubre, Nueva York, pp. 406-413.

Noizet, Vanessa (2011): Anatole Jakovsky (1907/1909?-1983): La trajectoire d'un critique d'art au XXe siècle. París, Université París IV-Sorbonne.

Noyes Platt, Susan (1988): "Modernism, Formalism, and Politics; The 'Cubism and Abstract Art' Exhibition of 1936 at The Museum of Modern Art". En: Art Journal, Vol. 47, 4, Nueva York, pp. 284-295.

Origines et développement de l'art International Indépendant (1937), París: Musée du Jeu de Paume.

Parigodis, Alexandra (2001-03): "González en el contexto del surrealismo: plûtot la vie". En: Kalías. Revista de Arte, 25-26, Valencia, 2001-2003, pp. 54-67.

Pierre, Arnauld (2002): “Jean Hélion et Albert E. Gallatin. Un aspect des échanges entre l'Europe et les Etats-Unis". En: Made in Usa, L'art américain 1908-1947. París: Réunion des Musées Nationaux, pp. 198-207.

Read, Herbert/ Lecomte, Marcel/ Scutenaire, Jean (1939): London Bulletin, 1, mayo, Londres.

Rousseau, Madeleine (1949): "Hans Hartung”. En: Cahiers d'Art, 2, París, pp. 217-220.

Smith, David (1956): "González: Firs master on the torch". En: Art News, 2, Nueva York.

Stavitsky, Gail (1990): The Development, Institutionalization, and Impact of the A.E. Gallatin Collection of Modern Art, Thesis Ph. D. dissertation. Nueva York, New York: University, vols. 2 y 7.

Tabart, Marie (1999): González Picasso dialogue. París: Centre Pompidou, Réunion des Musée Nationaux.

Thwaites, J. y M. (1936): "Surrealism and Abstraction-the search for subjective form". En: Axis, 6, Londres.

Tucker, William. (1977): The Lenguage of Sculpture. Londres: Thames and Hudson, 1977.

Stoulling, Claire (1991-1992): Hans Hartung dialogue avec Julio González: Peintures, dessins, sculptures, 1937-1949. París: La Maison des Arts Georges Pompidou, 1991, Valencia: Instituto Valenciano de Arte Moderno.

Sweeney, James Johnson (1949): "Preface". En: Rousseau, Madeleine; Domnick, Ottomar: Hans Hartung, Stuttgart: Domnick Verlag.

Wescher, Herta (1935): "Paris Notes". En: Axis, 3, pp. 28-29.

Zervos, Christian (1931): "La nouvelle génération”. En: Cahiers d’Art, 9-10, París, pp. 399-440.

Fecha de recepción: 24-III-2017

Fecha de aceptación: 23-XI-2017

Archivo Español de Arte, vol. XCI, n. ${ }^{\circ}$ 363, pp. 301-316, julio-septiembre 2018

ISSN: 0004-0428, eISSN: 1988-8511, https://doi.org/10.3989/aearte.2018.19 